\title{
Tropical Town and Other Poems (1918) de Salomón de la Selva: poemas panamericanos en tiempos de la Gran Guerra
}

\section{Tropical Town and Other Poems (1918) by Salomón de la Selva: Pan American poems at the time of the Great War}

Tatiana Suárez Turriza Universidad Pedagógica Nacional, México

Resumen: Tropical Town and Other Poems (1918) es el único poemario de Salomón de la Selva publicado en inglés, en el contexto de la Gran Guerra. Se le considera una obra de coyuntura entre dos culturas y tradiciones literarias. Este trabajo plantea la importancia de considerar su estudio en el ámbito de las letras hispánicas, entre otras razones, por su evidente relación con la tradición poética hispanoamericana. A partir del análisis crítico de los poemas, se evidencia la expresión de un discurso ideológico fundamentado en los ideales del panamericanismo, postura de implicaciones políticas que fue definitiva en la vida y obra del autor. Se analiza dicho discurso como una de las directrices temáticas que estructura y da unidad a la obra. Asimismo, se expone la calidad estética del poemario, a partir del análisis de algunos recursos poéticos.

Palabras clave: panamericanismo, literatura norteamericana, modernism, Gran Guerra, vanguardia. 
Abstract: Tropical Town and Other Poems (1918) is the only collection of poems by Salomón de la Selva published in English, in the context of the Great War. It is considered a book that joins two cultures and two literary traditions. In this paper, I underline the importance of studying De la Selva's work inside of the Hispanic Literature because, among other reasons, it has an evident relationship with Hispanic American poetical tradition. Through the critical analysis of the poems, it is possible to perceive the expression of an ideological discourse based in the Pan Americanism ideals - a doctrine that defined De la Selva's work and life-. This paper studies such a discourse as one of the topics that structures and unites the author's writing. At the same time, it analyses some of the poetical strategies, to show the aesthetic quality inherent to this collection of poems.

Keys words: Pan Americanism, American literature, Modernism, Great War, Avant-garde.

Recepción: 28 de septiembre 2017 Aceptación: 2 de febrero de 2018

\section{Poeta centroamericano en Nueva York}

Salomón de la Selva viajó a los Estados Unidos por primera vez de una beca de estudios del gobierno nicaragüense de J. Santos Zelaya; aunque al poco tiempo, a la caída del poder del mandatario, el gobierno le retiró el sustento económico, sólo que, gracias a sus propios esfuerzos, logró permanecer en ese país. Su primera estancia duró hasta 1910, cuando la muerte de su padre lo obligó a regresar a su natal León, Nicaragua; al año siguiente, en 1911, retornó a Estados Unidos, donde permaneció hasta $1921 .{ }^{1}$

${ }^{1}$ En 1921, el escritor mexicano José Vasconcelos, que iniciaba una cruzada educativa en su país, lo llamó a ocupar el lugar que había dejado Ramón López 
En cuestiones políticas, Salomón de la Selva mantuvo una postura crítica frente al país en el que se educó; su espíritu y dignidad centroamericanos marcaron los límites de su empatía y agradecimiento a Estados Unidos. En su "Acróasis en defensa de la cultura humanista" (1957), confiesa que al llegar por primera vez a Estados Unidos llevaba consigo el Ariel de Rodó, y lo llevaba, según recuerda, "no sólo bajo el brazo, sino que entre los pliegues de [su] cerebro juvenil", decidido a no dejarse "vencer por Calibán" (De la Selva, 1957: fol 1). ${ }^{2}$ En ese mismo texto reconoce, sin embargo, que la vida cultural estadounidense fue determinante para el fortalecimiento de su espíritu artístico. Estados Unidos, en particular Nueva York, le proporcionó una amplia formación artística e intelectual que difícilmente hubiera logrado de haber permanecido en su país. Se apropió de la lengua y de la literatura anglosajonas; fue asistente asiduo de actos culturales y de salones literarios neoyorkinos, en los que entabló amistad con la élite intelectual estadounidense; fue testigo y protagonista del renacimiento de la poesía en Estados Unidos, marcada por la aparición de las antologías de los imagistas (1914-1917). En la revista Poetry, órgano difusor del movimiento imagista, publicó sus primeros poemas.

Tropical Town and Other Poems, su primer poemario, apareció en Nueva York en 1918 bajo el sello de la prestigiosa casa editorial John Lane Company, asociada a The Bodley Head de Londres. Aunque De la Selva ya había publicado algunos de los poemas que compila en este libro en distintas revistas, ${ }^{3}$ Tropical Town significó

Velarde (1888-1921) al frente de la revista El Maestro. Entusiasmado por esta invitación, Salomón de la Selva decidió establecerse en México.

${ }^{2}$ Los borradores mecanografiados, y corregidos a mano, de este ensayo, "Acróasis en defensa de la poesía humanista", se encuentran en el Archivo Salomón de la Selva que resguarda el Acervo Histórico de la Biblioteca Francisco Xavier Clavigero de la Universidad Iberoamericana de la Ciudad de México.

${ }^{3}$ En una nota de agradecimiento, el mismo autor, menciona el nombre de dichas revistas: Century, Harper's Monthly, Pan American Magazine, de Nueva 
su verdadera presentación como poeta en lengua inglesa. El respaldo de la prestigiosa editorial garantizó la aceptación de su primera y única obra publicada en inglés en los círculos de escritores norteamericanos de la época. ${ }^{4}$ Pero el autor no permaneció en Nueva York para disfrutar de ese momento de triunfo y consagración literaria; el mismo año de la aparición de su poemario, De la Selva partió de esa ciudad rumbo a las trincheras de Flandes. ${ }^{5}$ Como resultado de su experiencia en la guerra escribiría los poemas de su primer libro en español: El soldado desconocido, que publicó en México en 1922.

York; Poetry de Chicago; Contemporary Verse, de Filadelfia, y Militia of Mercy.

${ }^{4}$ En la solapa que acompańaba esa primera edición, los editores apuntaron una breve valoración crítica de la obra y del autor, que merece citarse completa: "It is perhaps the mixture, not rare in Latin America, of Indian, Spanish and English blood in his veins, that has made Salomon de la Selva the representative poet of the Tropics that he is: savage in his passion for nature, proud in his love of country, subtle in his perception of spiritual values in all things. To strong individualism he adds a culture unusual in one so young, and thereby succeeds in interpreting to people of different traditions the very soul of his Latin America. He possesses a rich and faultless command of English, and at times employs resources of English prosody that reveal his scholarship. He has nurtured his innate gift in the art and literatura of all countries, but whether he sings a Rumanian folk ballad oraly ricin the manner of the Elizabethans, he is a Latin American through and through, and, whatever the form he uses, the soul of the poem is always his soul. Nor is he merely a Singer of songs; he has an ideal to give utterance to, he is the poet of Pan-Americanism, and equally dear to him are the volcanoes of Nicaragua and the White birches of New England" (Stanley, 1919: 259-259).

${ }^{5}$ Salomón de la Selva partió de Nueva York el 29 de julio de 1918 para iniciar su travesía hacia Flandes. Consiguió llegar a las trincheras en octubre de ese mismo año, y permaneció sólo hasta la primera semana de noviembre; su experiencia bélica fue mínima pero la tradujo poéticamente de manera intensa en El soldado desconocido (Vid. Montealegre, 2015: 165; Suárez, 2015: 137; Bolaños, 2009: $1-2)$. 
En "Nota sobre la otra vanguardia” (1979), José Emilio Pacheco enfatizó la trascendencia de El soldado desconocido (1921) para el estudio de la poesía vanguardista en México. Sobre Tropical Town and other poems, sin embargo, sólo comenta que es una obra "inconseguible" y la califica como "una curiosidad literaria, cuya importancia radica en permitirle [a su autor] el dominio del verso inglés" (Pacheco, 1979: 329). ${ }^{6}$ Sin duda, Tropical Town está lejos de ser un mero ensayo de formas poéticas anglosajonas; De la Selva sentó en esa obra las pautas estéticas de su poesía posterior en español, que Pacheco considera como obra inaugural de otra vanguardia en México. ${ }^{7}$

Debido a su singularidad, no es fácil ubicar esta obra en un ámbito o tradición literaria específica. Silvio Sirias la considera una obra de coyuntura entre dos culturas y dos tradiciones literarias primordiales, parte del legado hispánico literario de Estados Uni-

${ }^{6}$ Diez años después del ensayo de Pacheco, Miguel Ángel Flores, en su estudio introductorio a la edición de El soldado desconocido y otros poemas (1989) del Fondo de Cultura Económica, reconoce también no haber podido consultar ningún ejemplar de Tropical Town, y lo califica como "una verdadera rareza bibliográfica" (Flores, 2005: 7). Por fortuna, en la actualidad y desde hace ya varios años, se cuentan con algunas ediciones de esta obra, y su primera edición puede consultarse en Internet Archives: https://archive.org/details/tropicaltownand00selvgoog.

${ }^{7}$ El ejemplar que he consultado no conserva la solapa con la valoración crítica que aquí transcribo. Tuve noticia de ella por William Stanley Braithwaite, en su Anthology of Magazine Verse for 1918, publicada en 1919. La breve nota sobre Tropical Town and Other Poems se limita a reproducir la valoración crítica que figura en la solapa del libro. Conviene señalar que en 1914, en su reseńa del poema "A Tale from Faerieland" (1914), Pedro Henríquez Ureña alude al éxito del poemario de De la Selva, y menciona como prueba el que Braithwaite lo haya antologado: "el distinguido antologista Mr. Braithwaite, que recoge en un volumen las mejores poesías de cada año, ha decidido darle sitio de honor en la colección de 1915" (Henríquez Ureña, "Salomón de la Selva", 1977: 205). 
dos. ${ }^{8}$ En su opinión, los poemas de Tropical Town, aunque escritos en inglés, expresan una sensibilidad hispanoamericana. Esa misma impresión tuvo el editor del poemario, ya que en la presentación del libro refiere que a pesar de su perfecto dominio del inglés y de su maestría para adoptar formas poéticas de distintas tradiciones literarias, el autor de Tropical Town es sin duda latinoamericano, y el alma de su poema es un reflejo de su propia alma. ${ }^{9}$ Ése fue uno de los sellos distintivos de esa obra en el contexto anglosajón. Pedro Henríquez Ureña también destacó la singularidad de Tropical Town, y fue más específico al definir en qué consistía ese acento distinto que ofrecía esta obra ante la tradición literaria norteamericana:

Su poesía se distingue ya, en el país de lengua inglesa donde comenzó a escribir, porque posee elementos que no abundan en los Estados Unidos: imágenes delicadas y música verbal. La imaginación norteamericana propende al realismo, a las concepciones claras y sin ornamentos: cuando se exalta, tiende a lo vasto sin contornos, como en Emerson, como en Whitman, como ahora en Sandburg o Lindsay. Fuera de Poe, apenas hay imaginativo

${ }^{8}$ Escribe Silvio Sirias: "Tropical Town has fallen into the narrow gap between Latin American and U. S. Hispanic literature. Critics of Latin American literature have decided that it doesn't belong in their realm. They perceive it, for the most part, as a peculiar work, to be merely mentioned in passing when discussing the formation of this talented Nicaraguan poet. Perhaps it's time for critics in the United States to claim Tropical Town as part of the Hispanic-American literary legacy. The poems were the work of a poet of Latin American sensibilities who made his initial foray into the literary world in a language and an environment in which he felt, for the most part, very comfortable. The end result is an effort that is patently Hispanic-American, an enterprise that blends both the Anglo and Hispanic cultures and literary traditions (Sirias, 2000: 268-269). ${ }^{9}$ Salomón de la Selva "is a Latin American through and through, and, whatever the form he uses, the soul of the poem is always his soul" (Stanley, 1919: 259). 
del tipo de Coleridge, ni del tipo de Keats. Y en música verbal, la limitación no es menor (Henríquez Ureña, 1977: 155).

Una crítica más reciente, de María Augusta Montealegre, sostiene la percepción de que Tropical Town and Other Poems es "producto de un imaginario cultural que es diferente del norteamericano", que el poeta tradujo al verso formal inglés (Montealegre, 2015: 222). Desde mi lectura, el poemario propone la fusión o diálogo de horizontes culturales, de Norteamérica y Centroamérica, a través de los ideales del panamericanismo. Uno de los hilos temáticos que estructura y da unidad a Tropical Town and Other Poems es, precisamente, la expresión de ideales panamericanos. De ahí que los editores del libro bautizaran a su autor como "the poet of PanAmericanism”.

Mediante una intensa actividad intelectual y educativa, Salomón de la Selva y su amigo y tutor Pedro Henríquez Ureña difundieron una noción de panamericanismo que suponía una auténtica relación fraterna y justa entre los Estados Unidos y la América hispana; que se oponía de manera muy crítica a la interpretación, con fines de dominio, que Estados Unidos había hecho de esa doctrina.

Durante su estancia en Estados Unidos, y sobre todo en el tiempo que convivieron en Nueva York, los dos escritores centroamericanos unieron esfuerzos para rescatar lo que para ellos era esencial de la doctrina panamericana; a la vez que denunciaron los abusos que Estados Unidos había cometido contra algunas de las naciones más débiles de América, en especial, contra sus países de origen. Desde la misma palestra estadounidense, a través de publicaciones periódicas, discursos y discusiones públicas, defendieron el ideal bolivariano de una América unida por lazos de cooperación y de ayuda, de los países más adelantados hacia los más pobres, pero contemplando, como no lo hiciera Bolívar, a Estados Unidos. Por lo mismo, condenaron la "intervención" -armada- de Estados Unidos en los asuntos internos de los países hispanoamericanos. 
Ciertamente, la propuesta del Panamericanismo a principios del siglo XX se percibió como una idea de "dominación, el intento de Estados Unidos por instalar su liderazgo y su hegemonía económica y política en la región" (Marambio Castro, 2017: 6). Esta idea de "dominación" impulsó, sin embargo, la necesidad de conocer más sobre Latinoamérica, sobre la cultura y la historia de los vecinos del sur (Marambio Castro, 2017: 7).

En el ámbito intelectual y literario, la traducción se convirtió en un recurso fundamental para alcanzar esos ideales panamericanos de conocimiento y acercamiento cultural entre las dos Américas. Salomón de la Selva llevó a cabo una intensa actividad como traductor de la literatura y cultura hispanoamericana al inglés, y de la inglesa al español; pero su intención fue "rescatar" del discurso panamericano sus ideales más nobles de auténtica fraternidad y cooperación. Su propuesta panamericana es crítica y contestataria de la interpretación estadounidense, que se tradujo en acciones intervencionistas. El "arielismo" de Salomón de la Selva, en ese sentido, no se opone a su concepción del panamericanismo; el autor se mantuvo crítico y resistente frente a las aspiraciones de dominación política y cultural estadounidense, con sus implicaciones materialistas; así lo demuestra la abierta "defensa del humanismo" que expresa en su literatura.

En 1918, cuando aparece el poemario del escritor nicaragüense, la atención de los estadounidenses, y del mundo, se centraba en la Gran Guerra. El 2 de abril de 1917 el presidente Woodrow Wilson declaró la guerra contra Alemania y pidió al Congreso que su país participara en el conflicto europeo. El gobierno de los Estados Unidos declaró que, al tomar esta decisión, tenía el propósito de salvaguardar la democracia en el mundo; pero, irónicamente, en ese tiempo llevaba ya varios años infringiendo la soberanía nacional de Panamá, Haití, República Dominicana y Nicaragua, países hispanoamericanos donde tenía una imponente presencia militar. 
De esa manera había tergiversado los ideales panamericanos de convivencia y respeto entre las Américas. Ése es el ambiente de expectativa y tensión política que enmarca la aparición de Tropical Town. En su poesía, como se expondrá más adelante, expresa esas paradojas ideológicas y políticas.

Tropical Town and Other Poems se organiza en cuatro apartados: "My Nicaragua", "In New England and Other Lyrics", "In War Times" y "The Tale from Faerieland”. Pedro Henríquez Ureña juzgó, en su momento, que el primer apartado, "My Nicaragua”, es el que presenta mayor cohesión (Henríquez Ureña, 1977: 361). Sin embargo, los poemas del segundo apartado, "In New England", complementan la visión panamericanista que se plantea en el apartado que abre el libro, "My Nicaragua". Es decir, esos dos primeros apartados del libro condensan la concepción panamericanista que inspira el poemario; las dos secciones definen y mitifican los ámbitos geográficos y culturales que el poeta pretende conciliar: América del Norte y América del Sur.

\section{"My Nicaragua": postales poéticas, de sensibilidad hispa- noamericana, para Norteamérica}

Para Henríquez Ureña, "My Nicaragua" es "la parte más interesante del libro"; la define como una "colección de acuarelas sorprendentes por lo delicadas y justas. Principia con la acuarela más breve de todas, la que da título al libro, 'Tropical Town', y termina, saliéndose ya de la visión pictórica, con el inolvidable grito, 'rojo como flamenco', de la ceremonia panamericana." Estas "acuarelas" de paisajes tropicales plasman una imagen casi mítica de Nicaragua, representada por León, la ciudad natal del poeta. "Tropical Town”, “Tropical House”, "Tropical Park", “Tropical Morning”, "Tropical Dance”, “Tropical Rain”, “Tropical Afternoon”, “Tropical Life", “Tropical Childhood”, son algunos de los poemas de esta 
primera sección que ofrecen la visión panorámica de la riqueza y belleza geográfica, cultural e histórica de Nicaragua, a través de la evocación de los recuerdos del sujeto lírico. Desde el inicio, en el primer poema titulado "Tropical Town", el sujeto lírico afirma su calidad de extranjero, aclara que se encuentra lejos de su patria: "I come from there,/ And when I tire of hoping, and despair/ Is heavy over me, my thoughts go far,/ Beyond that length of lazy street, to where/ The lonely green trees and the white graves are" (De la Selva, 1918: 11). A través del recuerdo, el poeta delinea las primeras pinceladas de una imagen mítica de su ciudad natal León Nicaragua-. Crea una atmósfera de matices oníricos, donde el tiempo se presiente suspendido: una calle amplia y apacible, de solitarios y verdes árboles, y se alude, de manera simbólica, a la muerte: de tumbas blancas.

En el segundo poema, "Tropical House”, el sujeto lírico manifiesta el deseo de llevar al destinatario poético a ese espacio tropical y exótico de su patria: "When the Winter comes, I will take you to Nicaragua,- / You will love it there!” (De la Selva, 1918: 12). En su conjunto, los poemas de esta primera sección no sólo recrean el espacio paradisíaco de la infancia del poeta, también insisten en motivar al destinatario poético a que aprecie o reconozca la belleza y grandeza de Nicaragua. Teniendo en cuenta la postura panamericanista que inspira la obra, ese destinatario poético -que en algunos poemas, como el arriba citado, se manifiesta claramente a través del deíctico "You"- es, claramente, un ciudadano estadounidense.

"My Nicaragua" evoca la vida y la historia del país natal del poeta; algunos poemas refieren tradiciones populares, como "All Soul's Day", que describe la fiesta religiosa del día de muertos en Noviembre; hay otros más, que incorporan cantos y juegos populares infantiles, como "Tropical Dance", "The Midget Maiden”, "The Girl That Was Wise" o "Birds of Clay", los cuales completan 
la imagen mítica, casi edénica del país. La visión paradisíaca se irrumpe, por momentos, para denunciar la pobreza, la injusticia y otras difíciles circunstancias sociales y políticas que aquejan al país; pero se enfatiza la dignidad con la que el pueblo centroamericano afronta esas vicisitudes.

La crítica directa hacia los Estados Unidos aparece de manera más abierta en poemas como "The Haunted House of Leon", "A Song for Wall Street” y “The Dreamer's Heart Knows Its Own Bitterness". Para Steven White, estos poemas hacen del nicaragüense uno de los poetas con mayor conciencia política de su tiempo en el contexto literario de los Estados Unidos, en tanto que tematiza la injusta relación entre Estados Unidos y Latinoamérica. ${ }^{10}$

"The Haunted House of Leon" es el primer poema de acento político en el libro. Hace referencia a la leyenda de una casa embrujada en León, Nicaragua, saqueada y quemada por filibusteros americanos -como se advierte desde el título entre paréntesis: "(Burned by American Filibusters 1860)"-, a quienes el poeta califica como "Sons of the Devil". El poema relata también la tragedia de "la Juanita", a quien el "Diablo" ultrajó y asesinó en esa casa hechizada. La leyenda lleva implícita la crítica a las invasiones de Estados Unidos a Nicaragua. ${ }^{11}$ En ese sentido es particularmente

10 "Selva was perhaps one of the most politically-aware poets of his time. His perception of the unjust political relationship between the United States and Latin America, especially in a poem such as 'A Song for Wall Street', makes de la Selva unique among his contemporaries writing in the English language" (White, 1993: 123).

${ }^{11}$ Este relato se inspira en el hecho histórico de las invasiones del filibustero William Walker y su grupo denominado los "Inmortales", quienes en ese momento intervinieron en la guerra civil de Nicaragua, del lado de los demócratas. Walker obtuvo tal poder en Nicaragua que logró erigirse como su presidente, si bien tiempo después fue derrotado y expulsado. La figura de Walker ha pasado a la historia en Centroamérica como símbolo de la ambición o del imperialismo estadounidenses. 
interesante la declaración final del sujeto lírico, los dos últimos versos en los que advierte: "I will marry a Yankee girl/ And we will dare!" (De la Selva, 1918: 26). Como observa Silvio Sirias, en varios momentos del poemario, el poeta propone el maridaje entre los habitantes de esas dos naciones, como una solución posible al conflicto. ${ }^{12}$

"A song for Wall Street" se compone de cuatros estrofas de seis versos; cada una inicia con la repetición, retórica, de la interrogante que un supuesto interlocutor -el destinatario poético norteamericano- plantea al sujeto lírico:

In Nicaragua, my Nicaragua,

What can you buy for a penny there?-

A basketful of apricots, A water jug of earthenware, A rosary of coral beads And a priest's prayer.

And for two pennies? For two new pennies?The strangest music ever heard

All from the brittle little throat Of a clay bird, And, for good measure, we will give you A patriot's word.

And for a nickel? A bright white nickel?It's lots of land a man can buy... (27).

En las tres primeras estrofas se refiere la riqueza material, artística y espiritual, que el extranjero puede obtener de Nicaragua;

12 "The merging of both people, the American and the Nicaraguan, constitute a solution that De la Selva often poses to resolve many of the conflicts existent between the two nations" (Sirias, 2000: 268). 
se exalta la abundancia y la generosidad del país centroamericano. Pero la última estrofa imprime el acento dramático al poema.: "But for your dollar, your dirty dollar,/ Your greenish leprosy,/ It's only hatred you shall get/ From all my folks and me; So keep your dollar where it belongs/ And let us be!" (De la Selva, 1918: 27). Esos versos finales concentran el reclamo a la codicia estadounidense, que ha empañado los ideales del panamericanismo.

La crítica hacia los Estados Unidos en esta primera sección del libro va in crescendo hasta estallar en el "grito rojo como flamenco de la ceremonia panamericana”, como calificó Pedro Henríquez Ureña al poema “The Dreamer's Heart Knows its Own Bitterness”, subtitulado, entre paréntesis, "(A Pan-American Poem on the Entrance of the United States into the War") que cierra el apartado. Ese poema es el más extenso de la sección y representa el punto álgido de la crítica contra los Estados Unidos. Funciona, además, como "puesta en abismo" de la ideología panamericanista que se acrisola a lo largo de la obra. Es decir, el poema refleja, mediante una alegoría amorosa -en la que personifica al Sur como su "madre" y al Norte como su "novia"-, el tema que da unidad al poemario: el conflicto de un sujeto desgarrado entre sus aspiraciones de justicia y hermandad panamericanista y su conciencia amarga de los abusos del país del Norte:

To the South I said: "You are my Mother:

With your will you have shaped me, with your rich breasts fed;

Your daughters I call Sister, your sons, my Brother;

In my hour of need I will call on no other,-

You will close my eyes when I am dead" (38).

Y al Norte, Estados Unidos, lo presenta como su Novia:

To the North I said: "You are my Bride:

I have found you fair, you shall know me true; 
We will rise together, side by side;

On a day, you shall cherish my love with pride, For who praise my name shall honour you" (39).

El sujeto lírico declara su disposición al sacrificio, su intención de combatir como soldado en la guerra europea: "For its sake I would die the soldier's death"; "I would die in battle for the least of these lands"; ${ }^{13}$ pero también acusa a su "Novia" de no corresponderle, ya que se niega a respetar y tratar con dignidad a su Madre. Se trata de una evidente recriminación a los Estados Unidos por su actitud denigrante contra Latinoamérica; un amargo reclamo contra los agravios que el país del Norte ha cometido contra los países del Sur:

But now a cry like a red flamingo

Has winged its way to the Judgment gates:

My Nicaragua and Santo Domingo

Shorn in their leanness by the "famous States"!

Harried and thieved in their want, in their hunger, Their honour flaunted for a thing of laughter.... -You have done this because you are the stronger, Do you know what deeds may follow after? (42).

Finalmente, incita al Norte a ser congruente con su sentido de la justicia:

Will you let this thing be said of you, That you stood for Right who were clothed with Wrong?

${ }^{13}$ Es evidente la alusión al propósito del autor de enlistarse como soldado para combatir en los frentes de la Gran Guerra. De hecho, en 1918, cuando aparece el libro, Salomón de la Selva se encontraba en entrenamiento militar dentro del ejército estadounidense. 
That to Latin America you proved untrue?

That you clamoured for justice with a guilty tongue?

Hear me, who cry for the sore oppressed:

Make right this grievance that I bear in me

Like a lance point driven into my breast! (43).

El poema concluye con una plegaria que reitera el compromiso del Sur a apoyar la causa del Norte en la guerra europea, a pesar de las injusticias de que ha sido víctima: "The power of God made manifest,/ And I pledge the South shall never rest/ Till your task is accomplished and the world is free" (43). Aunque paradójica, esta declaración final es congruente con el ideal de fraternidad panamericana que defendía el autor.

\section{"In New England and Other Lyrics": canciones de "amor y odio" a la nueva Patria}

En "In New England and Other Lyrics", segundo apartado del libro, se compone de poemas dedicados a Nueva Inglaterra, "madre espiritual" de los Estados Unidos, que exponen el rostro indulgente de ese país. Puede advertirse en este apartado un hilo "narrativo" que refiere la gradual asimilación por parte del sujeto lírico de la nueva cultura, la anglosajona.

El brevísimo primer poema "Deliverance" sitúa al poeta en el nuevo espacio, en el que se siente aún ajeno:

What am I doing here, in New England?

All day long, till the end of the purple arfternoon,

Watching to see, over the hills of New England, The rising of the universal moon (47). 
La referencia a los espacios y al sentido de pertenencia a ellos, a lo largo del poemario, da cuenta de la identificación paulatina del sujeto lírico con la cultura del Norte, y del reclamo para que ese mismo proceso ocurra con el destinatario poético. Además, las descripciones de los espacios, en particular de los paisajes naturales, son de notable simbolismo.

En "Deliverance" el poeta utiliza el adjetivo "universal" para definir la luna que el sujeto lírico espera ver levantarse por encima de las montañas de Nueva Inglaterra; la "luna universal" funciona como símbolo de la fusión cultural que el sujeto lírico va a experimentar a partir del encuentro con Estados Unidos.

Más adelante, en el poema "The Secret”, después de la bellísima descripción de un atardecer de primavera en Nueva Inglaterra, ${ }^{14}$ el sujeto lírico confiesa que aún no logra adaptarse a ese ambiente anglosajón lleno de misterio, que lo atemoriza y le provoca deseos de huir: "I wanted/ to pack my things and run away" (49). Pero en el siguiente poema, "Confidences", se suscita un cambio; el poeta asume el papel de enlace entre las dos culturas, representadas en los siguientes versos por las montañas y los volcanes, de Nueva Inglaterra y de Nicaragua respectivamente:

The hills have gathered round me

To hear me tell

Of the deep volcanoes

Where the old gods dwell (50).

En la última estrofa se vislumbra ya, de manera simbólica, la adaptación del sujeto lírico a su nuevo entorno, a través de la refe-

${ }^{14}$ Sólo una estrofa de este logrado poema, "The Secret", corrobora el talento del autor para la descripción poética del paisaje: "When the cool sun was setting/ The sky spread out her hair/ Over the pillowy mountains/ Heaped for her comfort there,/ And I saw, like bathing women,/ White birches tossing in the air" (De la Selva, 1918: 49). 
rencia a su participación activa en un juego infantil denominado "cacería de brujas":

\section{Dance, all you little children,}

And I will play with you!

I am afraid of witches

Also; I burn them too.... (50).

En el poema último de la sección, "Finally", el sujeto lírico corrobora que ha superado sus temores, se ha adaptado al ambiente y cultura de Nueva Inglaterra, y ésta lo ha acogido como a un hijo: "Finally, after months of being shy,/ An Autumn and a Winter of looking at each other/ With a suspecting eye,/ It is good to know at last that I have found you,/ New England, little mother!” (51). El sujeto lírico encuentra, al fin, el lado sensible y cálido de esa nueva tierra, que en un principio le pareció gélida, insondable y le provocó desconfianza: "You are not feelingless, you are not cold"; "You are not heartless, you are not unkind" (51). La lectura de este poema, en especial de los versos arriba citados, echa luz sobre la interpretación del enigmático poema titulado "Portrait".

En "Portrait" el sujeto lírico describe su encuentro con alguien, un personaje al que califica de frío e inescrutable, "like water frozen to its depth" (48), y a quien, a pesar de sus grandes esfuerzos, no consigue conmover, ni logra amar: "I tried all ways I could to love him:/ I crept up closer and I leaned above him./ [...] But he was frozen through and through,/ How deep he was I never knew" (48). Leído en retrospectiva, estos versos adquieren más sentido, ya que el encuentro que se describe alude a la primera impresión que tuvo el sujeto lírico al llegar a Nueva Inglaterra. Dicho de otro modo, el poema refiere el primer enfrentamiento del poeta con el pueblo de los Estados Unidos. En "Finally", entonces, el sujeto lírico ha superado esa primera impresión y ha descubierto por fin lo que se esconde tras esa apariencia "dura y fría" de sus habitantes. 
Como lo hiciera con Nicaragua en el primer apartado, en esta segunda sección el poeta exalta la belleza y riqueza geográfica, cultural y espiritual de Nueva Inglaterra y sus habitantes. En "Finally", por ejemplo, presenta algunos breves cuadros de la vida cotidiana de su gente, enfatizando, en esa representación de la vida provinciana estadounidense, la devoción religiosa de los habitantes.

Cabe recordar que también en los poemas dedicados a Nicaragua, el poeta destaca la misma cualidad en su presentación del pueblo centroamericano. El devenir de la vida cotidiana de la "ciudad tropical" se rige por los eventos religiosos, por sus creencias, y también por la superstición.

La religiosidad de los pueblos de América es motivo central de la propuesta ideológica panamericanista que estructura y da unidad temática al poemario. El sentimiento religioso aparece en el poemario como uno de los lazos que unen al pueblo hispanoamericano con los habitantes de Nueva Inglaterra. Por encima de los distintos referentes religiosos que tienen ambos pueblos -el catolicismo de los nicaragüenses, frente al protestantismo o puritanismo de los estadounidenses-, lo que importa para el sujeto lírico, y así lo enfatiza, es el sentimiento religioso, y algunos valores derivados de esa religiosidad: la fe, la caridad o el amor al prójimo. Es decir, se propone la igualdad de estos pueblos en lo más esencial y primitivo, por encima de sus diferencias de lengua, cultura o historia. Los siguientes versos, del poema "Finally", confirman la intención de mostrar el vínculo, religioso en este caso, que une las dos patrias del poeta:

I will go to all the places where ever I have gone, And last to Nicaragua, where I will tell my people: “They haven't any cathedrals, their worshipping is done In little bits of churches, painted white, with a pointed steeple, But their God is the God of us, their Christ is Mary's son (53-54). 
Las otras composiciones que el autor agrupa en esta segunda sección, aunque no se refieren a Nueva Inglaterra, de cierto modo se relacionan con el encuentro cultural que vivió el poeta a su llegada a Estados Unidos, donde se le facilitó el acercamiento al arte y a la literatura universal. El poema "Cellini at the Metropolitan Museum” registra el asombro del poeta ante el arte del Renacimiento italiano. La contemplación del exquisito salero esculpido por Benvenuto Cellini, que perteneció al príncipe Rospigliosi de Roma, da pie a que el poeta reflexione sobre la inmortalidad y el tiempo infinito; preocupaciones metafísicas que continuarán presentes en su poesía en español.

Al igual que en la sección dedicada a Nicaragua, en el segundo apartado hay poemas inspirados en la tradición oral centroamericana, de tono infantil, como las tres composiciones agrupadas bajo el título: "Three Songs My Little Sister Made". Hay otro conjunto de poemas de tema amoroso, titulado "Three Songs", en los que se nota también el acento de oralidad, ahora vinculado con la tradición estadounidense. Asimismo, hay un soneto en el que poeta reformula motivos amorosos caros a la tradición poética renacentista, como la imagen de la mariposa que va al encuentro del sol, motivo clásico en los sonetos de Petrarca. ${ }^{15}$ No faltan tampoco los poemas de tema religioso, inspirados en la tradición bíblica cristiana, como "Song of the Magdalen".

Pedro Henríquez Ureña resumió bien el contenido variado de esa y las siguientes secciones de Tropical Town and Other Poems:

${ }^{15}$ La mariposa es símbolo del amante que, atraído por la luz de la amada, es consumido por el amor. El motivo de la mariposa también aparece en el poema "Make-Believe", una de las "Three Songs My Little Sister Made" antes mencionadas; pero en esta composición el poeta recrea el motivo a partir de una rima infantil de Nicaragua: “¡Mariposa, mariposita, / la del ala azul, / vamos a volvernos locas / de tanta luz!” (60). Fiel al humanismo petrarquista, Salomón también introduce motivos profanos tomados de la tradición grecolatina y los une con elementos del cristianismo. 
hay versos de ira y de amor por la tierra en que [Salomón de la Selva] escribía sus versos ingleses (¡oh Rubén Darío! autor a un tiempo mismo de la "Oda a Roosevelt" y la "Salutación al Águila"); hay canciones inspiradas en motivos populares o en las deliciosas rimas infantiles de su hermana; hay poemas inspirados en obras de arte -Bach, Giorgione, Cellini-; hay creaciones de fantasía que se agitan en "danzas etéreas", como el encantador Cuento del pais de las hadas; hay salmos de amor ideal y hay gritos crueles sobre el hambre y el odio ( Henríquez Ureńa, 1977: 157).

Ante la riqueza formal y temática de Tropical Town and Other Poems, como bien auguró Henríquez Ureña, el lector o estudioso puede sentirse perdido. Pero es cierto también que se pueden identificar hilos temáticos bien delimitados que dan estructura y unidad a la obra. En mi opinión, las dos primeras secciones del libro tienen más cohesión, y constituyen por sí mismas casi una obra independiente. Como se ha intentado mostrar, el tema del panamericanismo, que apunta hacia la fusión de culturas que vive y promueve el poeta, se encuentra definido en esos dos primeros apartados. Las dos secciones presentan mayor unidad o cohesión temática: dan cuenta de la "paradoja emocional y política" del sujeto lírico ante el conflicto que enfrenta a sus dos "patrias". En una suerte de juego especular, en esos dos primeros apartados el poeta establece correspondencias entre las dos naciones.

\section{"In War Time", el entrenamiento del poeta soldado}

Me interesa terminar este acercamiento a Tropical Town and Other Poems con el apartado tercero titulado "In War Time". Consta de seis poemas de tema bélico, que representan el antecedente más directo de su obra en español El soldado desconocido (1922). En el primer poema, "A Prayer for the United States", se describe el acontecimiento de la guerra en términos bíblicos, como el cum- 
plimiento de las profecías del Apocalipsis: "Apocalyptic blasts are ravaging over-sea./ With lure of flag and conquest the harlot War is wooing./ The horse John saw in Patmos its dread course is pursuing.-/ I pray the Lord He shelter the stars that shelter me" (De la Selva, 1918: 71).

En "Hatred" aparecen, de nuevo, símbolos bíblicos: la imagen del dragón, alegoría cristiana del mal, ${ }^{16}$ representa el odio ("hatred") que enardece a la humanidad, o a los pueblos, en tiempo de guerra: "When hunger crawls/ Up to the heart, and draws/ Its dragon form about it, and its claws/ Make all the limbs to ache; when darkness falls/ Upon the bloodshot eyes/ While yet the imperturbèd skies/ Are full of light" (72).

Como se ha advertido, a lo largo del poemario se establecen vínculos o correspondencias entre los valores católicos y los de la religión protestante norteamericana. La alusión a los textos bíblicos es, en ese sentido, significativa, ya que los protestantes, a diferencia de los católicos, conciben la Biblia como única fuente de "revelación absoluta y que posee fuerza redentora y salvadora" (Troeltsch, 2011). Es decir, el autor parece tener el cuidado de contextualizar con referencias bíblicas los valores religiosos (católicos y protestantes) que exalta en su poesía, y de ese modo enfatizar lo común en ambas religiones y culturas. ${ }^{17}$

${ }^{16}$ En el capítulo 13 del Apocalipsis el dragón se asocia con el "Maligno" o el "Diablo", cuya aparición vaticinaba guerras, pestes y otros infortunios.

${ }^{17}$ En la propuesta arielista de Rodó, que plantea la formación de un Estado común entre las patrias hispanoamericanas, son continuas las alusiones a la herencia española compartida, pero sobre todo la celebración de valores católicos que "anteponían la dignidad" al talento y los logros materiales, la "fe religiosa a los éxitos mundanos, lo tradicional a lo moderno, lo artístico y elegante a lo fundacional y práctico" (Vitacca Morales, 2017: 278). Pero en el panamericanismo expresado en Tropical Town, que contempla la comunidad con Estados Unidos, se redefine esa exaltación de valores católicos; aunque se mantiene la perspectiva 
El poema "Hatred" cierra con una reflexión que sugiere la necesidad de renovar el rumbo de la literatura ante la inefable realidad bélica: "All else is antique rhetoric and serves/ For literature to cheat the hard-strung nerves/ Of people weary with the weight of war" (72). Para Steven White, los poemas de guerra de Tropical Town corresponden al estilo de la poesía inglesa de tema bélico en su primera etapa. Según explica, dicha poesía, caracterizada por "la reflexión pasiva sobre las ideas patrióticas imperantes", fue algo que proliferó antes de que Inglaterra y el mundo experimentaran la magnitud de la tragedia, de sus horrores. Estoy de acuerdo en el evidente acento patriótico de los poemas, pero éste no sólo responde al estilo de la poesía inglesa de guerra de ese tiempo, también se explica por la ideología panamericanista que expresa y refuerza la unidad temática de la obra.

Además, no todos los poemas de la obra traslucen entusiasmo patriótico. En el poema "December 1916", ${ }^{18}$ la contemplación del paisaje invernal de Nueva Inglaterra inspira al sujeto lírico a meditar sobre el destino fatal de la humanidad, envuelto en una alternancia perpetua de guerra y paz. El paisaje adquiere connotaciones simbólicas. En la primera estrofa, el sujeto lírico espera ver caer la nieve sobre la árida tierra de Nueva Inglaterra: “...earth's wrinkled face/ Is frozen stiff, as if some death/ Painful and sudden had struck it so./ There are no signs as yet of snow" (73). Y la situación se convierte en alegoría de la añoranza de paz en el mundo: "(No signs of peace, the world's heart saith)" (73). A los ojos del poeta, el

arielista en tanto que se enfatiza la "dignidad" de la América Hispana y se incrimina el "materialismo" anglosajón.

${ }^{18}$ Le fecha que da título al poema puede ser que remita a un acontecimiento importante de la Gran Guerra: el final de la larga y cruenta batalla de Verdún, que duró del 21 de febrero al 19 de diciembre de 1916. Fue el enfrentamiento con la mayor cantidad de pérdidas humanas, y se le considera símbolo de la resistencia francesa. Fue durante esta batalla cuando el comandante francés Robert Nivell pronunció la famosa frase “¡No Pasarán!” 
paisaje de Nueva Inglaterra semeja un campo de batalla: "I almost could think some battle here/ Was fought, and mangled bodies lie, / Frozen and filthy, under the drear/ Gaze of the sun, the moon, the sky" (73). En la tercera y última estrofa, la nieve cubre por fin a New England, y el poeta, de pronto, cae en la cuenta de que bajo la paz se esconde la guerra latente -como debajo de la nieve, la tierra-:

But God is punctual and snow will come

(And peace will come, the world's heart saith.)

And earth will hide her troublesome

Face of despair, semblance of death.

But this frozen horror that we know

Shall be terrible still, under the snow.

(Peace shall be terrible, the world's heart saith) (73).

En 1917, Salomón de la Selva recibió entrenamiento militar en los valles de Nueva Inglaterra. El poema "Drill” recrea uno de esos días en el que, mediante un arrebato místico, el soldado poeta, sujeto lírico, asume la decisión de ir a la guerra como camino de comunión con Dios, en tanto que entraña la voluntad de sacrificio; de modo que la visión de la Gran Guerra adquiere matices de misticismo (Suárez, 2015: 140-141). Para White, "In De la Selva’s poem, the potential of violence is a quasi-mystical source of ecstatic release that illuminates the world, increasing its natural beauty" (White, 1993: 127). Esta concepción "casi mística” de la guerra se expresa con imágenes simbolistas, que delatan el apego del autor al modernismo dariano. Se puede decir que en "Drill” se aprecia la plástica expresión de lo absoluto a la que, según Ricardo Gullón, 
aspiraban los poetas simbolistas -emulados, a su vez, por los modernistas del ámbito hispánico-: ${ }^{19}$

Now, as never before,

From the vastness of the sky

Falls on me the sense of war.

Now, as never before, comes the feeling that to die

Is no duty vain and sore.

Something calls and speaks to me,-

Cloud and hill and stream and tree;

Something calls and speaks to me

From the earth, familiarly.

I will rise and I will go

As the rivers flow to sea,

As the sap mounts up the tree

That the flowers may blow.-

God, my God,

All my soul is out of me! (75).

Otro componente notable de estos poemas sobre la guerra es la expresión del sentimiento religioso. En "Drill”, como se puede notar, se trata de una religiosidad matizada de panteísmo, en tanto que los elementos de la naturaleza se intuyen como proyección de lo divino: "God, my mortal eyes/ Cannot resist the onslaught of your skies!/ I am no wind, I cannot rise and go/ Tearing in madness to the woods and sea;/ I am no tree,/ I cannot push the earth and lift and grow; I am no rock/ To stand unmovable against this shock" (76). La aspiración al "absoluto", que se expone en este

${ }^{19}$ Como ha expuesto Ricardo Gullón, algunos modernistas también admiraron, y siguieron en su obra, el ejemplo de los grandes místicos españoles, como San Juan de la Cruz, Juan de Ávila o Santa Teresa. De esta manera el misticismo se fundió con la poética simbolista en el crisol de corrientes estéticas que absorbió el modernismo (Gullón, 1990: 23-24). Esta fusión también se da en la poesía de Salomón de la Selva. 
poema a través de un sentimiento religioso panteísta, denota la raigambre romántica y modernista del poema. Además fundamenta, en un sentido alegórico, la pretensión de unidad inherente a la concepción del panamericanismo que defiende el autor.

En los dos últimos poemas de "In War Time", el poeta recurre a la tradición medieval para crear una alegoría amorosa de la relación del soldado en combate con su nación. En "Ode to the Woolworth Building”, el famoso edificio de estilo gótico de Nueva York, que en ese tiempo era el más alto de la ciudad, se transfigura a los ojos del poeta en una hermosa doncella que espera la llegada de su amado. El poeta pregunta al edificio si no siente pena por los jóvenes que parten a la guerra y lo equipara con la catedral de Reims, considerada símbolo nacional de Francia, que sufrió bombardeos alemanes durante la Gran Guerra. En "The Knight in Gray”, el poeta acude de nuevo a las alegorías medievalistas y románticas; el sujeto lírico se transfigura en un caballero que combate y muere en la guerra para que perdure su leyenda. En uno de los cuartetos que componen el poema, el caballero declara su intención de convertirse en leyenda: "But nothing matters except this thing:/ My arms are rhythmic to my breath,/ And I must live the songs I sing/ To save my songs from death" (83). Estos versos pueden interpretarse como uno de los postulados artísticos del autor: la idea de que las canciones, "the songs", deben tener arraigo en la vivencia o propia experiencia para que trasciendan, para que "se salven de la muerte". No en vano, don Pedro Henríquez Ureña finalizó su famosa y citada reseña sobre Tropical Town recordando esa declaración que aparece en "The Knight in Gray", que tenía un sentido profético que, ya para entonces, se había confirmado con hechos: "Y todo lo ha vivido el poeta. Él lo dice: 'He de vivir las canciones que canto para salvarlas de la muerte.' Sí, aunque el 'decir las cosas bien' aparezca como signo de artificialidad a los ojos de los superficiales, es verdad" (Henríquez Ureña 1977: 289). 


\section{Desde el "País de las hadas"}

La continuación de la tradición poética del siglo XIX, anglosajona e hispanoamericana, es uno de los sellos distintivos de la propuesta de Salomón de la Selva, en el contexto de las vanguardias. Esa "defensa" de la tradición -decimonónica, y de otras épocas- en su poesía, es parte de su propuesta estética de entrecruzamiento, fusión, de tradiciones y de culturas, afín a su idealismo panamericano.

La última sección del poemario, The Tale from Faerieland, es el mejor ejemplo de esa recuperación -y renovación- de las formas tradicionale ${ }^{20}$ Los poemas de este apartado, pletóricos de imágenes delicadas y de exacerbada musicalidad, rasgos inusitados en la tradición poética anglosajona, forman un tapiz poético de evidente inspiración dariana, modernista. Pero también en su tejido se advierten los hilos de las formas tradicionales del verso inglés, que su

${ }^{20}$ El poema "The Tale from Faerieland" apareció por vez primera en julio de 1915, en una revista de renombre, The Forum. Pedro Henríquez Ureña publicó, el mismo año, en Las Novedades de Nueva York una breve pero sugerente reseña, que encomia el poema "de exquisito corte prerrafaelista": "Las Novedades desea no dejar sin mención el reciente triunfo del poeta Salomón de la Selva. Aunque nació en Nicaragua (hace apenas veintiún años) y aunque maneja con elegancia el castellano, su verdadera lengua literaria es el inglés. Se le conocía ya y se le estimaba en los círculos literarios de Estados Unidos; pero el triunfo que lo coloca en la primera fila de los poetas norteamericanos es el que acaba de obtener con la publicación, en la aristocrática revista The Forum, de su poema $A$ Tale from Fairyland (Cuento del país de las Hadas)" (Henríquez Ureña, 1977: 205-206). También incluye la traducción al español de algunos de sus versos. El poema de Salomón, aún en la versión en prosa que ofrece Henríquez Ureña, tiene la sutileza y exquisitez de la poesía dariana: "Y había palabras como rosas, y palabras resonantes como el vuelo súbito de multitud de pájaros. Y palabras de selvas, como hojas, que, siempre trémulas, hacían murmurantes los versos. Y una palabra era luna; una sílaba argentada, y casta, y plena de conjuros. Y una palabra era sol; y era redonda, y era cálida, y tenía sonido de oro...” (1977: 206). 
autor aprendió de la poesía de su admirada -y amada- Edna Saint Vincent Millay. En los primeros versos del poema que da nombre a la sección, en voz de un crítico conservador que opina sobre la textura y composición de un "tapiz" ("lyric tapestry"; evidente metáfora de la composición poética), se alude a esa inclinación por formas y temas antiguos: "The colours are too gaudy and the style / Is obsolete' -Hi slips were black with bile./ 'The subject is Antique; you should have fraught/ Your pretty dreams with valiant, modern/ though" (De la Selva, 1918: 90-91). Entre los poemas de este apartado final, resalta, por contraste, el poema "To those who have been indiferent to the Pan American movement", que retoma el grito, más bien reclamo, panamericano. El estilo, más prosaico, de este poema contrasta con la musicalidad y sutileza de los otros de esta sección. La inserción de ese poema en este apartado final refuerza el sentido de unidad del poemario, a partir de la expresión del discurso idealista panamericano.

En Tropical Town... es posible reconocer el germen de temas, motivos y rasgos de estilo que prefiguran su obra en español más apreciada, El soldado desconocido (1922), en el escenario de la vanguardia hispanoamericana. El acercamiento a su poesía en inglés permite apreciar con mayor justeza la singularidad de su obra. En ese sentido, este poemario debe concebirse, siguiendo la propuesta de Sirias, como una obra de coyuntura, que concierne a la tradición literaria de ambas culturas, la hispánica y la anglosajona.

Cabe recordar, por último, que en sus páginas se mantiene vivo el reclamo que alguna vez hiciera Salomón de la Selva a los Estados Unidos, en su famoso discurso pronunciado en 1917, en una ceremonia panamericana, que causó la indignación del presidente Roosevelt, quien presidía el evento: "Mi tierra es tan grande como sus pensamientos; tan grande como sus esperanzas y sus aspiraciones... Amar a los Estados Unidos - como yo los amo-cuesta tan gran esfuerzo cuando mi propio país es ultrajado por la Nación 
del Norte. No puede existir el verdadero panamericanismo sino cuando se haga plena justicia a las naciones débiles" (Henríquez Ureña, 1977); protesta que en las circunstancias actuales refuerza su vigor y sentido.

\section{Bibliografía}

Arellano, Jorge Eduardo, 1969, "Pedro Henríquez Ureña y Salomón de la Selva", en Homenaje a Salomón de la Selva 19591969, Ernesto Gutiérrez (ed.), Cuadernos Universitarios, León, Nicaragua, pp. 112-118.

Bolaños, Luis, 2009, "Salomon de la Selva as a soldier of the Great War", Hallali. Revista de estudios culturales sobre la Gran Guerra y el mundo hispánico, núm. 4. Disponible en: http://www.revistahallali.com/2009/06/29/ luis-bolanos-salomon-de-la-selvaas-a-soldier-of-the-great-war/ (21/XIII/2014).

Darío, Rubén, 1998, "Salutación al Águila”, en Poesía de Rubén Dario, FCE, México.

De la Selva, Salomón, 1918, Tropical Town and Other Poems, John Lane/The Bodley Head, Nueva York/Londres.

1957, “Acróasis En Defensa De La Cultura Humanista”, en [Ms.] Archivo Salomón de la Selva del Acervo Histórico de la Biblioteca Francisco Xavier Clavigero de la Universidad Iberoamericana de la Ciudad de México, 10 de abril.

Flores, Miguel Ángel, 2005, "Introducción”, en El soldado desconocido y otros poemas, FCE, México, pp. 11-50.

García Caderón, 2003, "Panamericanismo y paniberismo", en América Latina y el Perú del novecientos. Antología de textos, Universidad Nacional Mayor de San Marcos, Lima, pp. 127-140.

Gullón, Ricardo, 1990, Direcciones del modernismo, Alianza, Madrid. 
Henriquez Ureña, Pedro, 1977, Obras completas, t. 3, Juan Jacobo de Lara (ed.), Universidad Nacional Pedro Henríquez Ureña, Santo Domingo.

, 1998, Ensayos, José Luis Abellán y Ana María Barrenechea (eds.), FCE/ALLCA XX, Colección Archivos, Madrid.

Marambio Castro, María Soledad, 2017, Elogio del amateur. Traducción y resistencia en la era del Panamericanismo (EE.UU. 1889-1945), Tesis de Doctorado en Filosofía, The City University of New York.

Montealegre, María Augusta, 2015, Las ideas estéticas y políticas de las vanguardias en Nicaragua (1918-1933). Salomón de la Selva y el autodenominado movimiento nicaragüense de vanguardia, Tesis doctoral, Universidad de Salamanca.

Pacheco, José Emilio, 1979, "Nota sobre la otra vanguardia", Revista Iberoamericana, núm. 45, Universidad de Pittsburgh, enero-junio, pp. 327-334.

Sirias, Silvio, 2000, “The Recovery of Salomón de la Selva's Tropical Town", en Recovering the U. S. Hispanic Literary Heritage, vol. 3, María Herrera-Sobek y Virginia Sánchez Corrol (eds.), University of Houston, Houston, pp. 268-269.

Stanley Braithwaite, William, 1919, Anthology of Magazine Verse for 1918, Small Maynard and Company, Boston.

Suárez Turriza, Tatiana, 2015, "El soldado desconocido (1922) de Salomón de la Selva: la Gran Guerra vista y vivida por un poeta centroamericano", Península, vol. X, núm. 2, CEPHCIS/ UNAM, Mérida, julio-diciembre, pp.135-158.

Troeltsch, Ernest, 2011, Protestantismo y mundo moderno, Eugenio Ímaz (trad.), FCE, México.

Vitacca Morales, Ignacio, 2017, "Herencia y alteridad en el panamericanismo hispánico del siglo XX: José Enrique Rodó y Manuel Baldomero Ugarte”, en Fronteras contemporáneas: iden- 
tidades, pueblos, mujeres y poder, Cristian Ferrer González y Joel Sans Molas (coords.), Universidad Autónoma de Barcelona, Barcelona, pp. 271-290.

White, Steven F., 1991, "Salomón de la Selva, poeta comprometido de la otra vanguardia”, Revista Iberoamericana, núm. 42, Universidad de Pittsburgh, Pittsburgh, pp. 915-921.

White, Steven, 1993, "Salomon de la Selva: Testimonial Poetry and World War I", en Modern Nicaraguan Poetry: Dialogues with France and the United States, Assoiated University Press, Lewisburg/Londres/Toronto, pp. 119-143 